\title{
Gender gaps in the path to adulthood for young females and males in six African countries from the 1990s to the 2010s
}

\author{
Jane Mariara ${ }^{1}$, Andy McKay², Andy Newell ${ }^{2,3}$ and Cinzia Rienzo ${ }^{4}$
}

\author{
* Correspondence: \\ a.mckay@sussex.ac.uk \\ ${ }^{2}$ Department of Economics, \\ University of Sussex, Brighton BN1 \\ 9SL, UK \\ Full list of author information is \\ available at the end of the article
}

\begin{abstract}
In this paper, we study on a comparative basis the school-to-work transition of young women and young men in six countries in sub-Saharan Africa, and we examine how this has evolved over recent years, based on the data collected by Demographic and Health Surveys. We examine educational attainments and the nature of early jobs young people are able to obtain, as well as considering their relationship to marriage and fertility outcomes, factors which are likely to be particularly relevant for young women. A pooled regression analysis shows that educational levels have increased substantially and gender gaps have narrowed in most countries. Access to better jobs has improved much more slowly with unchanging gender gaps in most countries, so that agriculture is still the dominant sector of employment for most young men and women. We model correlates of key educational outcomes and access to different types of jobs those controlling for individual- and household-level characteristics, including marital status, presence of children and wealth. Attaining a high level of education is unsurprisingly critical for access to the best jobs and is also associated with young women delaying marriage and childbearing.
\end{abstract}

JEL Classification: 121, J21, J24, 055

Keywords: First job, Education, School-to-work transition, Sub-Saharan Africa

\section{Introduction}

Youth employment is a major challenge across the world, and especially pressing in sub-Saharan Africa, the one world region where the youth population continues to grow. According to the World Bank, 11 million young people enter the labour market each year (Filmer and Fox 2014). But higher recent growth in this region has not yet succeeded in generating a commensurate increase in job opportunities (African Development Bank et al. 2012). At the same time, the young people in sub-Saharan Africa-as elsewhere in the world-are becoming increasingly educated over time (in terms of years of schooling and attainment), though levels remain low compared to other world regions. The limited number of formal sector work opportunities means that the vast majority of labour market entrants are likely to work in agriculture, household businesses or otherwise in the informal sector, typically earning low incomes. Job creation is a major challenge in

(c) The Author(s). 2018 Open Access This article is distributed under the terms of the Creative Commons Attribution 4.0 International License (http://creativecommons.org/licenses/by/4.0/), which permits unrestricted use, distribution, and reproduction in any medium, provided you give appropriate credit to the original author(s) and the source, provide a link to the Creative Commons license, and indicate if changes were made. 
sub-Saharan African countries though urgently required to avoid wasting the opportunity offered by their youth populations.

While both young males and females face these issues, the challenges are often significantly greater for young females. International data (e.g. World Development Indicators) and other sources show that secondary school completion rates and literacy rates are lower for young females than males; young females are also less likely to work than young males (even if rates of both female and male labour force participation are high compared to other world regions). To add to this, fertility rates in sub-Saharan Africa are higher than other world regions, with young women typically marrying and having children at younger ages. This impinges much more on young females than young males-who anyway tend to marry later. The young women in this region would appear to reconcile the competing claims of work and family on their time by working more in household agricultural or non-farm activities or casual wage work (Kabeer 2012). Expanding women's opportunities for full and productive paid employment and improving their access to education/adult literacy programs have been identified as some of the key strategies to increase women's economic empowerment in Africa (Wekwete 2014, and Kabeer 2012), which in turn carries many other benefits.

Work on the school-to-work transitions of young people in the developing world is strongly associated with the International Labour Organisation (ILO; notably based on their School to Work Transition Surveys (SWTS) conducted in 36 countries in the developing world (Elder 2009; O'Higgins 2017). Among many other studies, Elder and Kring (2016) address gender issues analysing 32 SWTS surveys. In earlier work, Parent (2006) studied the work and life transitions made over the following 10 years of a group of people in Burkina Faso who were 15-19 years old in 1993. He finds that among those with no schooling, the vast majority of men simply make the transition from household worker to head of household and the vast majority of women stay in domestic work. What emerges is that education beyond primary level seems to be a necessary condition for gaining work outside the household. This study suggests that dropping out of school early imposes a major penalty in terms of the breadth of work options. Shamchiyeva et al. (2014) use SWTS data to analyse the school-to-work transition for 15-25 years old in Tanzania and find that girls are more likely (than boys) to have dropped out of secondary school, and if they did, they are more likely to have done so for financial reasons.

These studies though do not also take account of fertility. A number of analytic studies though have sought to address the challenging deep issues of endogeneity that affect the educational, fertility and work choices of young women. A number of studies have looked at the impact of early childbirth on educational outcomes of young women, using different techniques to try to address the endogeneity issues to seek to find causal relationships (e.g. Ranchhod et al. 2011 and Ardington et al. 2015 for South Africa; Herrera and Sahn: Early childbearing, school attainment and cognitive skills: evidence from Madagascar, forthcoming, for Madagascar). Agüero and Marks (2011) use infertility as an instrument in looking at the causal impact of children on female labour force participation. Other studies seek to consider education, marriage/childbirth and labour supply together in one analysis. Heath and Mobarek (2015) study these choices in the case of Bangladesh, allowing for the proximity or not of garment factories (which offer many employment opportunities for young women) as an exogenous intervention. They use this to model educational attainment, marriage, childbirth and time of starting work, using duration models for some of these outcomes. Marchetta and Sahn (2016) study educational, marriage, childbirth and work 
outcomes for young women in Senegal, based on high-quality data that enable plausible exclusion restrictions at each stage. With a broadly similar econometric approach to Heath and Mobarek, they find that access to primary and secondary schools and improved school quality both increase grade attainment and the chances of staying on at school. Additionally, using data on the girls' parents, they find that higher levels of parents' education reduce both the chances at a given age of marriage and the age of first birth. Ozier (2015) uses a regression discontinuity design linked on a key cut-off score in the Kenya Certificate of primary education examination that substantially increases the likelihood of secondary school admission, to look at the impact of secondary schooling on human capital attainment, teenage pregnancy and better labour market outcomes.

In this paper, rather than performing an in-depth country study, we undertake a six-country comparative analysis of the school-to-work transition, seeking to compare young women with young men where feasible, examining changes over time and comparing across the countries. We focus on six countries in Eastern and West Africa at different levels of development: Burkina Faso, Ethiopia, Ghana, Kenya, Tanzania and Uganda. ${ }^{1}$ We focus mostly on the key questions of educational attainment and access to specific types of job for young women and men, which are clearly strongly interrelated. We also consider factors associated with this, including marital status and presence of young children. As noted, our focus is on the gender gap in these outcomes, how this has evolved over time and how this differs across the six countries. Such an approach clearly requires comparable data, and so we use data from Demographic and Health Surveys ${ }^{2}$ (DHS; Macro International 2006) for periods of time from the 1990s to the 2010s, in order (a) to understand development over time across the countries and (b) to eliminate, or minimise, temporal and international differences in survey questions and method. Our approach does not enable the endogeneity concerns to be addressed (which anyway is likely to require a country-specific approach that could probably differ by country), but we believe it identifies important trends and differences across countries.

Our analysis finds that over the periods of time considered here (which vary by country given the need for comparable data), secondary enrolment and literacy rates increased everywhere, and gender gaps fell in many cases. We find that there has been an expansion in the number of more highly skilled jobs in all countries, but numbers remain low, much less than the increase in educational levels, and there are continued gender gaps in most countries. Many young people continue to work in agriculture, and many young women do not work. Early marriage or cohabitation is a particular challenge for young women; they leave school early, lack access to good jobs or do not work at all.

The paper is structured as follows. Section 2 presents the data source we use for the six countries, the DHS surveys, discussing their strengths and limitations. Section 3 then presents a descriptive analysis of the key outcomes based on this data source, while Section 4 presents the country-level analysis of changes over time using a difference in differences approach to look at changing gender gaps. Section 5 then presents a multivariate analysis of the correlates of key educational and work outcomes of interest, after which Section 6 offers some summary conclusions.

\section{Data sources}

Our intention in this paper is to analyse the outcomes in relation to education and labour markets for young women, compared with young men. Our interest is to compare 
between the six countries of the project, as well as to examine changes over time within each country and to make comparisons between young women and young men, who may face many of the same challenges. In making this analysis, we will also consider other relevant factors and notably early experiences of marriage or childbirth.

Such analysis necessarily requires the use of data sources that are comparable between the countries and over time. Each of the six countries has multiple household surveys which collect information on the variables of interest here and which are often comparable over time within the country, but they are generally quite different from one country to another, raising challenges for cross-country comparability. Labour force surveys have not been conducted in all these countries, and are often less frequent. In this paper, we base our analysis on the Demographic and Health Surveys (DHS), which have been collected on multiple occasions in all the countries, which are broadly comparable across countries and over time and which collect information in each of the areas of interest. While this may not be the most obvious source for data on labour in particular, the surveys do collect information on this which with judicious use is comparable within and between countries.

The DHS surveys in all these six countries are nationally representative and have been conducted between three and six times. They are based on three main questionnaires. A major focus is on the women's questionnaire, asked to women in the reproductive age range (15-49 years) and which collects a large amount of information about the women themselves and about their children. In addition to this, a second questionnaire collects information on the households in which these women reside. A third questionnaire asks a smaller set of questions to those asked to women, though broadly similar in nature, to men aged 15 years and above. The samples of men are smaller than those of women. In general, the core elements of these questionnaires are the same between countries and between one round and the next within countries, though additional elements have been added over time.

The survey does collect information on all three key areas of interest for this paper: education, work and childbirth/marriage. Given the nature of the DHS surveys, with its major focus on collecting data on demographics and health-related issues, they are an excellent source of precise information on childbirth and marriage/cohabitation. But the surveys also collect a range of additional relevant information beyond demographics and health. For instance, the surveys collect the level of completed education and current educational attendance is collected for all individuals, and respondents are asked to read a card to assess literacy. All individuals are asked if they currently work, and some limited information is collected about that work including the occupation, the employment status (self-employed, unpaid family worker, employee outside the household) and whether it is seasonal. All this information is available for both men and women, based on essentially the same questions.

It is important to recognise that there is less detail in DHS surveys on education and labour compared to many regular household surveys. For many questions relevant to this paper, it would be helpful to have more information on the nature of education and work than is available from this source. The DHS is an excellent source of very high-quality information on childbirth in particular, something often collected less precisely in household surveys (where for example it is often difficult to match mothers and children). But the critical advantage of the DHS survey is that information on all three aspects are available for the same people, in a way which is comparable over time 
within countries and in particular which is comparable between countries. No other survey could enable the six-country comparison we make here. Further, the summary estimates the surveys give of educational attainment and labour outcomes are consistent with other sources, and the data quality in these areas is likely to be much better than summary statistics from World Development Indicators and other sources that are commonly used in cross-country comparison. They also enable disaggregation at the country level according to different criteria, such as location and wealth.

Some limitations though need to be recognised. This particularly applies to the labour data, where sometimes, the precise classification of occupations differs from one country to another (or over time within countries). In addition, while the question about labour force participation is the same everywhere, this is not a labour force survey and it remains possible that the interpretation of what "working" means might not have been consistently applied everywhere. These issues are important and need to be recognised. Here, we take care to analyse this data in a way to ensure consistency across countries and over time as best as we can. This means for example choosing not to use some questions or occupational categories where we cannot be confident of comparability.

The approach taken in this paper is to compare the latest survey available in each country (which ranges from 2010 to 2014 depending on the country) with the earliest DHS survey which we judge to be sufficiently comparable. The time period covered here ranges from 11 years in the case of Ethiopia (where the first DHS survey was conducted in 2000) to 21 years in the cases of Ghana and Kenya. The fact that we are comparing different lengths of time needs to be allowed for when comparing changes between countries.

In this paper, we focus on the educational levels young people attain and the types of jobs they can obtain as a result. For the most part, we focus on those in the 15 to 29 age range. The UN generally refers to youth as those in the 15 to 24 age range, though in Africa is sometimes wider, and most of these countries would consider those in the 15 to 29 age range as youth. However, we do sometimes also consider subsets of this. We also take account of marital/cohabitation status and number of children, which are important outcomes in their own right but also potentially very important correlates of the educational and work outcomes above. In the analysis, we also use as a key correlate a measure of the wealth of the household in which the individual currently lives. DHS surveys do not collect information on household consumption or income, but they do collect information on key assets owned by households and on housing characteristics. Macro International, who conduct the DHS surveys, have used these to construct household asset indices for each survey using factor analysis. We make extensive use of a standardised version of this in the analysis.

\section{Some descriptives}

We begin by looking at the percentage of young women and men currently attending school by age, up to age of 22 after which few are still in full-time education (Table 1). Over time, comparing the earlier and later year, this shows a substantial shift to staying later in education for both young men and women. The data also show substantial gender differentials from the age of 15 upwards in the earlier year in all countries; by the later year, gender differentials are substantially reduced in all countries among 15 year olds, but from around 17 years onwards, there are still quite large gender differentials in most 
Table 1 Percentage of young women in education, by current age

\begin{tabular}{|c|c|c|c|c|c|c|c|c|c|}
\hline \multirow[t]{2}{*}{ Country } & \multirow[t]{2}{*}{ Year } & \multicolumn{8}{|l|}{ Age } \\
\hline & & 15 & 16 & 17 & 18 & 19 & 20 & 21 & 22 \\
\hline \multicolumn{10}{|l|}{ Women } \\
\hline \multirow[t]{2}{*}{ Burkina Faso } & 1998 & 11.6 & 10.7 & 8.6 & 8.3 & 4.2 & 6.1 & 5.8 & 2.6 \\
\hline & 2010 & 40.8 & 32.6 & 22.0 & 18.9 & 15.5 & 12.0 & 11.2 & 9.1 \\
\hline \multirow[t]{2}{*}{ Ethiopia } & 2000 & 33.2 & 30.8 & 29.1 & 19.6 & 17.9 & 9.1 & 8.6 & 6.7 \\
\hline & 2011 & 70.9 & 67.0 & 60.8 & 43.4 & 33.5 & 22.7 & 21.9 & 18.6 \\
\hline \multirow[t]{2}{*}{ Ghana } & 1993 & 53.0 & 43.1 & 28.1 & 16.0 & 11.5 & 7.1 & 5.7 & 5.6 \\
\hline & 2014 & 68.3 & 54.7 & 48.7 & 27.1 & 20.2 & 11.3 & 10.4 & 10.3 \\
\hline \multirow[t]{2}{*}{ Kenya } & 1993 & 76.9 & 70.9 & 53.1 & 31.7 & 20.2 & 10.0 & 10.2 & 5.3 \\
\hline & 2014 & 91.5 & 85.4 & 73.8 & 50.5 & 39.6 & 24.5 & 18.5 & 13.8 \\
\hline \multirow[t]{2}{*}{ Tanzania } & 1996 & 61.2 & 40.7 & 25.5 & 12.0 & 7.0 & 5.2 & 1.9 & 2.1 \\
\hline & 2010 & 58.6 & 47.2 & 45.3 & 26.6 & 20.2 & 10.6 & 6.7 & 2.9 \\
\hline \multirow[t]{2}{*}{ Uganda } & 1995 & 45.6 & 24.8 & 21.0 & 11.7 & 7.9 & 5.3 & 5.2 & 3.4 \\
\hline & 2011 & 86.5 & 74.0 & 58.1 & 39.6 & 22.6 & 12.5 & 11.0 & 6.3 \\
\hline \multicolumn{10}{|l|}{ Men } \\
\hline \multirow[t]{2}{*}{ Burkina Faso } & 1998 & 21.5 & 17.9 & 16.8 & 13.9 & 15.1 & 11.7 & 9.7 & 4.4 \\
\hline & 2010 & 41.8 & 34.1 & 34.0 & 30.1 & 28.5 & 20.3 & 24.1 & 17.8 \\
\hline \multirow[t]{2}{*}{ Ethiopia } & 2000 & 47.1 & 48.1 & 36.8 & 37.0 & 51.5 & 23.2 & 28.3 & 17.9 \\
\hline & 2011 & 69.9 & 63.4 & 64.3 & 47.7 & 48.5 & 36.5 & 38.3 & 22.3 \\
\hline \multirow[t]{2}{*}{ Ghana } & 1993 & 60.5 & 48.4 & 55.6 & 30.4 & 29.4 & 8.7 & 14.3 & 11.8 \\
\hline & 2014 & 71.1 & 58.4 & 59.9 & 40.9 & 34.6 & 24.6 & 24.3 & 21.3 \\
\hline \multirow[t]{2}{*}{ Kenya } & 1993 & .. & .. & .. & .. & .. & 26.4 & 19.2 & 13.9 \\
\hline & 2014 & 95.0 & 89.3 & 83.1 & 70.6 & 51.3 & 38.6 & 29.1 & 24.6 \\
\hline \multirow[t]{2}{*}{ Tanzania } & 1996 & 69.4 & 57.0 & 35.8 & 29.3 & 23.6 & 14.4 & 6.3 & 3.1 \\
\hline & 2010 & 66.6 & 55.6 & 50.4 & 52.8 & 32.3 & 29.2 & 16.8 & 12.9 \\
\hline \multirow[t]{2}{*}{ Uganda } & 1995 & 67.8 & 46.0 & 54.5 & 36.4 & 47.2 & 30.2 & 20.8 & 17.0 \\
\hline & 2011 & 85.9 & 80.1 & 75.2 & 50.8 & 47.3 & 35.3 & 31.0 & 13.7 \\
\hline
\end{tabular}

Source: Authors' calculation from DHS survey data. ".." denotes that the 1993 DHS survey of men for Kenya only interviewed those aged 20 and above. The numbers of observations on which this table is based range from 1635 for the case of Ghana in 1993 to 13,385 for the case of Kenya in 2014

countries. In other words, there are now very limited gender differentials in attendance in the primary school age range, but gender differentials remain from early- to mid-secondary education onwards, to the disadvantage of females.

One factor which is important here in relation to school attendance is early marriage, especially of young females. The percentage of young females and males who are cohabiting (or married) by specific ages is presented in Table 2. The data show strikingly that large numbers of young women are already cohabiting or married by the ages of 16 or 17. This is particularly the case in the earlier year everywhere, but it persists for many women into the later year in all countries. By contrast, very few young men are married by the age of 18 anywhere (except Tanzania in the earlier year-and this is still substantially less than the number of women). It is very clear that when women marry or cohabit at young ages, they do so with older men.

Table 3 illustrates clearly that marriage or cohabiting often marks the end of education. While the same also applies to most men, there are many fewer married men in these age 
Table 2 Percentage of young women and men who are married by a given age

\begin{tabular}{|c|c|c|c|c|c|c|c|c|c|}
\hline \multirow[t]{2}{*}{ Country } & \multirow[t]{2}{*}{ Year } & \multicolumn{8}{|l|}{ Age } \\
\hline & & 15 & 16 & 17 & 18 & 19 & 20 & 21 & 22 \\
\hline \multicolumn{10}{|l|}{ Females } \\
\hline \multirow[t]{2}{*}{ Burkina Faso } & 1998 & 6.7 & 9.8 & 33.8 & 56.5 & 72.0 & 83.1 & 83.4 & 91.9 \\
\hline & 2010 & 5.6 & 10.8 & 30.5 & 48.0 & 66.3 & 76.3 & 78.9 & 79.9 \\
\hline \multirow[t]{2}{*}{ Ethiopia } & 2000 & 6.5 & 17.6 & 21.0 & 36.4 & 42.1 & 57.6 & 59.6 & 62.1 \\
\hline & 2011 & 6.1 & 10.3 & 16.1 & 28.8 & 41.0 & 54.3 & 49.8 & 60.9 \\
\hline \multirow[t]{2}{*}{ Ghana } & 1993 & 2.3 & 6.1 & 16.7 & 32.5 & 38.4 & 58.9 & 58.9 & 61.5 \\
\hline & 2014 & 0.2 & 2.6 & 3.3 & 8.2 & 20.3 & 29.2 & 26.4 & 35.3 \\
\hline \multirow[t]{2}{*}{ Kenya } & 1993 & 3.6 & 4.9 & 10.4 & 25.3 & 29.6 & 47.2 & 47.2 & 52.6 \\
\hline & 2014 & 1.0 & 4.1 & 8.7 & 18.4 & 28.6 & 38.7 & 49.9 & 59.5 \\
\hline \multirow[t]{2}{*}{ Tanzania } & 1996 & 3.8 & 11.1 & 18.8 & 32.9 & 48.6 & 59.2 & 65.2 & 69.0 \\
\hline & 2010 & 0.0 & 0.0 & 2.1 & 1.0 & 3.9 & 13.3 & 15.5 & 27.9 \\
\hline \multirow[t]{2}{*}{ Uganda } & 1995 & 19.0 & 30.4 & 45.7 & 64.6 & 71.1 & 74.9 & 75.3 & 78.1 \\
\hline & 2011 & 0.8 & 5.6 & 21.4 & 32.8 & 44.9 & 61.5 & 62.3 & 69.2 \\
\hline \multicolumn{10}{|l|}{ Males } \\
\hline \multirow[t]{2}{*}{ Burkina Faso } & 1998 & 0.0 & 1.0 & 0.0 & 0.9 & 7.6 & 6.3 & 8.3 & 24.4 \\
\hline & 2010 & 0.0 & 0.0 & 0.0 & 4.0 & 5.3 & 15.5 & 16.2 & 28.9 \\
\hline \multirow[t]{2}{*}{ Ethiopia } & 2000 & 0.0 & 0.0 & 0.0 & 4.2 & 0.4 & 10.7 & 5.1 & 14.3 \\
\hline & 2011 & 0.6 & 0.0 & 1.5 & 2.7 & 7.2 & 14.0 & 15.9 & 31.8 \\
\hline \multirow[t]{2}{*}{ Ghana } & 1993 & 0.0 & 0.0 & 0.0 & 4.3 & 5.9 & 8.7 & 14.3 & 17.1 \\
\hline & 2014 & 0.0 & 0.0 & 0.0 & 1.2 & 1.2 & 1.6 & 7.9 & 11.7 \\
\hline \multirow[t]{2}{*}{ Kenya } & 1993 &. &. & .. & .. & .. & 8.5 & 12.7 & 12.1 \\
\hline & 2014 & 0.0 & 0.0 & 0.2 & 0.4 & 2.6 & 3.9 & 10.4 & 17.6 \\
\hline \multirow[t]{2}{*}{ Tanzania } & 1996 & 2.9 & 11.1 & 16.8 & 29.8 & 36.6 & 52.3 & 54.6 & 70.1 \\
\hline & 2010 & 0.0 & 0.0 & 0.4 & 7.2 & 14.6 & 8.4 & 16.9 & 19.6 \\
\hline \multirow[t]{2}{*}{ Uganda } & 1995 & 0.0 & 0.0 & 2.9 & 23.9 & 17.2 & 31.8 & 47.6 & 52.3 \\
\hline & 2011 & 0.0 & 0.0 & 0.0 & 0.7 & 11.2 & 8.7 & 24.6 & 28.4 \\
\hline
\end{tabular}

Source: Authors' calculation from DHS survey data. The numbers of observations on which this table is based range from 1615 for the case of Ghana in 1993 to 13,594 for the case of Kenya in 2014

ranges. While the direction of causality between getting married or cohabiting and leaving school is unclear, early female marriage is strongly associated with the increased gender gap in educational attendance between males and females seen from the age of 16 onwards.

The occupational status of young people aged 21 to 29 years is presented in Table 4 . In all countries and in other earlier and later surveys, very few people in this age range are still in education. In all countries, though, many young women in this age range do not work, whereas this is the case for very few men. The proportions of women not working are high in Kenya and Ethiopia and relatively low in Burkina Faso and Ghana, but in all cases, they are substantially higher than the number of men who do not work. Among those working, agriculture dominates for women in Tanzania, Uganda and Burkina Faso, and these are also the three countries where the share of women working in agriculture increased between the earlier and later year. Smaller but still large numbers of women work in agriculture in the other countries, and there the shares fell. Agriculture dominates even more as the employment for young men in this age range, 
Table 3 percentage of married young women in education, by age

\begin{tabular}{|c|c|c|c|c|c|c|c|c|c|}
\hline \multirow[t]{2}{*}{ Country } & \multirow[t]{2}{*}{ Year } & \multicolumn{8}{|l|}{ Age } \\
\hline & & 15 & 16 & 17 & 18 & 19 & 20 & 21 & 22 \\
\hline \multirow[t]{2}{*}{ Burkina Faso } & 1998 & 0.0 & 0.0 & 0.0 & 0.7 & 0.0 & 0.8 & 0.5 & 1.4 \\
\hline & 2010 & 0.0 & 9.1 & 3.7 & 3.9 & 4.0 & 2.1 & 1.6 & 2.8 \\
\hline \multirow[t]{2}{*}{ Ethiopia } & 2000 & 0.6 & 0.3 & 6.4 & 5.2 & 1.7 & 1.7 & 0.1 & 0.6 \\
\hline & 2011 & 24.2 & 12.9 & 3.3 & 5.7 & 6.7 & 3.0 & 5.5 & 6.6 \\
\hline \multirow[t]{2}{*}{ Ghana } & 1993 & 0.0 & 10.0 & 0.0 & 0.0 & 3.6 & 0.8 & 2.8 & 1.8 \\
\hline & 2014 & 0.0 & 0.0 & 0.0 & 1.5 & 0.0 & 3.4 & 5.3 & 1.2 \\
\hline \multirow[t]{2}{*}{ Kenya } & 1993 & 0.0 & 0.0 & 2.3 & 1.5 & 0.0 & 2.0 & 0.4 & 3.5 \\
\hline & 2014 & 7.8 & 1.6 & 0.9 & 1.6 & 3.7 & 2.9 & 2.6 & 4.8 \\
\hline \multirow[t]{2}{*}{ Tanzania } & 1996 & 0.0 & 0.0 & 1.7 & 0.0 & 0.0 & 3.0 & 0.4 & 1.1 \\
\hline & 2010 & 0.0 & 0.0 & 2.8 & 0.0 & 0.1 & 0.0 & 1.1 & 0.0 \\
\hline \multirow[t]{2}{*}{ Uganda } & 1995 & 6.2 & 2.1 & 1.4 & 1.2 & 0.2 & 0.6 & 0.7 & 0.9 \\
\hline & 2011 & 31.5 & 1.2 & 4.8 & 0.0 & 0.4 & 1.9 & 0.0 & 1.8 \\
\hline
\end{tabular}

Source: Authors' calculation from DHS survey data. The numbers of observations on which this table is based range from 487 for the case of Ghana in 2014 to 2642 for the case of Burkina Faso in 2010

but in all countries except Uganda, the share of men working in agriculture fell over between the earlier and later period.

Small numbers of young people, female or male, work in professional, managerial, technical or clerical jobs (which we refer to for convenience as "white-collar jobs"), but shares are higher in Ghana and Kenya then elsewhere. Men have better access to these jobs than women everywhere except Uganda in 2011, and in all countries and for both genders, the proportion working in these jobs increased. Shares though remain low outside of Ghana and Kenya. The miscellaneous category of occupations (which includes a wide range) increased everywhere for both females and males between the earlier and later year, suggesting increased diversification of work. There are therefore some positive messages in the changing patterns of work even if better quality jobs may not have kept up with the expansion of education.

Finally, Table 5 reports on a key outcome of education: being functionally literate. Literacy rates have increased over the periods considered here, substantially so in Ghana. Females have lower literacy rates than males everywhere, but over this period, both Kenya and Uganda showed much larger increases in female literacy than in male literacy, at least reducing the gender gap. The same table reports literacy rates for white-collar workers and shows that they have much higher scores, close to $100 \%$ in many cases. The high scores may be selection, and probably mostly are, but it could also be that white-collar work improves literacy. One other perhaps surprising and suggestive result of note is that among white-collar workers, the literacy proportions are uniformly lower for young men than for young women, so on average, white-collar women are more literate than their male counterparts. Perhaps, they have to be in order to access these jobs.

These results show significant improvements in educational outcomes over time, and reductions in gender gaps, but with the remaining gaps seemingly associated in part with the tendency of women to form relationships at younger ages than men. Across all countries, women are more likely not to work and fewer women hold the better quality jobs. But in some countries, women who do work might be at least as likely to work in white-collar jobs as men, this is the case in Ethiopia, Kenya and Uganda. 
Table 4 Distribution of young people by occupation in six African countries

\begin{tabular}{|c|c|c|c|c|}
\hline \multirow[b]{2}{*}{ Burkina Faso } & \multicolumn{2}{|l|}{ Men } & \multicolumn{2}{|c|}{ Women } \\
\hline & 1998 & 2010 & 1998 & 2010 \\
\hline Not working still in school & 0.6 & 1.8 & 0.9 & 3.1 \\
\hline Not working or in school & 19.7 & 19.0 & 4.6 & 2.1 \\
\hline Professional, managerial, technical or clerical & 0.8 & 2.3 & 3.9 & 6.6 \\
\hline Agriculture & 38.4 & 44.6 & 62.5 & 50.7 \\
\hline Other & 40.4 & 32.3 & 28.1 & 37.5 \\
\hline Ethiopia & 2000 & 2011 & 2000 & 2011 \\
\hline Not working still in school & 1.2 & 2.2 & 1.8 & 1.2 \\
\hline Not working or in school & 33.9 & 38.0 & 1.8 & 1.6 \\
\hline Professional, managerial, technical or clerical & 2.4 & 5.8 & 4.4 & 8.8 \\
\hline Agriculture & 36.7 & 23.6 & 77.8 & 65.7 \\
\hline Other & 25.9 & 30.4 & 14.2 & 22.7 \\
\hline Ghana & 1993 & 2014 & 1993 & 2014 \\
\hline Not working still in school & 1.3 & 1.9 & 2.3 & 2.2 \\
\hline Not working or in school & 20.6 & 18.3 & 9.7 & 6.2 \\
\hline Professional, managerial, technical or clerical & 2.6 & 12.0 & 8.1 & 18.7 \\
\hline Agriculture & 33.0 & 14.2 & 51.3 & 24.6 \\
\hline Other & 42.5 & 53.6 & 28.6 & 48.2 \\
\hline Kenya & 1993 & 2014 & 1993 & 2014 \\
\hline Not working still in school & 1.1 & 2.3 & 1.2 & 3.5 \\
\hline Not working or in school & 42.8 & 25.3 & 4.2 & 3.5 \\
\hline Professional, managerial, technical or clerical & 7.5 & 12.5 & 10.0 & 14.3 \\
\hline Agriculture & 20.5 & 17.3 & 42.4 & 17.2 \\
\hline Other & 28.2 & 42.6 & 42.2 & 61.5 \\
\hline Tanzania & 1996 & 2010 & 1996 & 2010 \\
\hline Not working still in school & 0.3 & 0.8 & 0.8 & 2.7 \\
\hline Not working or in school & 42.8 & 13.2 & 1.6 & 3.3 \\
\hline Professional, managerial, technical or clerical & 3.0 & 0.0 & 1.7 & 4.5 \\
\hline Agriculture & 42.7 & 56.0 & 67.3 & 56.0 \\
\hline Other & 14.2 & 27.2 & 28.6 & 33.5 \\
\hline Uganda & 1995 & 2011 & 1995 & 2011 \\
\hline Not working still in school & 0.6 & 1.0 & 2.5 & 1.0 \\
\hline Not working or in school & 35.0 & 22.1 & 3.4 & 1.4 \\
\hline Professional, managerial, technical or clerical & 3.3 & 6.8 & 4.5 & 5.9 \\
\hline Agriculture & 44.6 & 47.0 & 66.1 & 66.2 \\
\hline Other & 16.6 & 23.1 & 23.4 & 25.5 \\
\hline
\end{tabular}

Source: Authors' calculation from DHS survey data. The numbers of observations on which this table is based range from 1412 for the case of Ghana in 1993 to 9169 for the case of Ethiopia in 2011

\section{A regression analysis of gender gaps and their changes over time}

We focus now on gender gaps and their evolution over time in two key educational outcomes and two job outcomes which can be defined consistently across the different 
Table $\mathbf{5}$ Literacy by gender and occupation: proportion of respondents given the top grade in a literacy test

\begin{tabular}{|c|c|c|c|c|c|}
\hline \multirow[t]{2}{*}{ Country } & \multirow[t]{2}{*}{ Year } & \multicolumn{2}{|c|}{ Women } & \multicolumn{2}{|l|}{ Men } \\
\hline & & All & White-collar workers & All & White-collar workers \\
\hline \multirow[t]{2}{*}{ Burkina Faso } & 1998 & 0.10 & 0.97 & 0.21 & 0.97 \\
\hline & 2010 & 0.22 & 0.95 & 0.32 & 0.75 \\
\hline \multirow[t]{2}{*}{ Ethiopia } & 2000 & 0.25 & 0.97 & 0.44 & 0.94 \\
\hline & 2011 & 0.38 & 0.97 & 0.57 & 0.93 \\
\hline \multirow[t]{2}{*}{ Ghana } & 1993 & 0.21 & 0.75 & 0.37 & 0.66 \\
\hline & 2014 & 0.59 & 0.96 & 0.70 & 0.94 \\
\hline \multirow[t]{2}{*}{ Kenya } & 1993 & 0.72 & 0.96 & 0.89 & 1.00 \\
\hline & 2014 & 0.84 & 0.94 & 0.87 & 0.96 \\
\hline \multirow[t]{2}{*}{ Tanzania } & 1996 & 0.65 & 0.91 & 0.76 & 0.88 \\
\hline & 2010 & 0.70 & 0.83 & 0.77 & 0.97 \\
\hline \multirow[t]{2}{*}{ Uganda } & 1995 & 0.37 & 0.90 & 0.56 & 0.89 \\
\hline & 2011 & 0.58 & 1.00 & 0.61 & 0.83 \\
\hline
\end{tabular}

Source: Authors' calculations from DHS survey data

datasets we are using. On education, it is clear from the analysis of the previous section that being literate is a necessary-though far from sufficient-condition for access to better quality jobs. We choose then to focus on this outcome and on individuals having some level of secondary education, a level to which many young people in these countries still do not reach. In all countries, individuals would be expected to be in secondary school by the age of 15 if they were following the normal educational pattern, though many drop out of school before this point or are in lower classes than they should be for their age. In terms of jobs, we focus on two categories which can be clearly defined consistently across all countries and years. The first category are those working in a professional, managerial, technical or clerical job (loosely referred to as "white-collar" work), an activity that definitely requires at least literacy and often higher educational attainments to enter. Secondly, we study those people working in agriculture, an activity which does not have educational requirements to enter and which most people could therefore participate in. While the data is not collected as to whether the white-collar jobs are in the public or private sector, the detailed occupational classification suggests that both are well represented. The vast majority of the agricultural work is self-employment, though some are also wage labourers. We define the educational variables for those in the 15-20-year age range, some of whom may still be in school, and the work variables or those aged from 21 to 29 years inclusive, the majority of whom will give left full-time education; but we do some sensitivity analysis around these ranges.

We undertake a regression analysis for each country to identify the extent of gender gaps in these four key outcome variables and how these have evolved over this time. To do this, the earlier and later datasets for women and men for each country are pooled together, and we then run OLS regressions for each outcome as a function of a gender dummy, a dummy for the later year, the interaction of these two variables and controls which can reasonably considered exogenous. These controls are as follows: the age in years of the individual, geographic location (regions, standardised between the two waves, interacted with urban/rural), household size and number of children in the 
Table 6 Regressions for educational outcomes based on pooled country-level data

\begin{tabular}{|c|c|c|c|c|c|c|}
\hline Coefficient & Burkina Faso & Ethiopia & Ghana & Kenya & Tanzania & Uganda \\
\hline \multicolumn{7}{|c|}{ If individuals have some secondary education } \\
\hline \multirow[t]{2}{*}{ Male } & $0.078^{* * *}$ & $0.042^{* * *}$ & 0.033 & $0.114^{* * *}$ & 0.007 & $0.100^{* * *}$ \\
\hline & {$[0.016]$} & {$[0.012]$} & {$[0.026]$} & {$[0.042]$} & {$[0.017]$} & [0.021] \\
\hline \multirow[t]{2}{*}{ Later year } & $0.222^{* * *}$ & $-0.012^{* *}$ & $0.609^{* * *}$ & $0.280^{* * *}$ & $0.262^{* * *}$ & $0.283^{* * *}$ \\
\hline & {$[0.015]$} & {$[0.006]$} & {$[0.015]$} & {$[0.013]$} & {$[0.011]$} & {$[0.021]$} \\
\hline \multirow[t]{2}{*}{ Male $\times$ later year } & -0.007 & -0.013 & -0.006 & $-0.142^{* * *}$ & $0.058^{* *}$ & $-0.124^{* * *}$ \\
\hline & {$[0.019]$} & {$[0.014]$} & {$[0.030]$} & {$[0.043]$} & {$[0.023]$} & {$[0.028]$} \\
\hline N & 8348 & 13,459 & 4412 & 12,928 & 6150 & 5534 \\
\hline$r^{2}$ & 0.178 & 0.272 & 0.416 & 0.174 & 0.241 & 0.148 \\
\hline Female baseline value & 0.093 & 0.124 & 0.114 & 0.231 & 0.061 & 0.160 \\
\hline \multicolumn{7}{|l|}{ Literacy status } \\
\hline \multirow[t]{2}{*}{ Male } & $0.075^{* * *}$ & $0.152^{* * *}$ & 0.041 & $0.086^{* * *}$ & $0.082^{* * *}$ & $0.153^{* * *}$ \\
\hline & {$[0.018]$} & {$[0.018]$} & {$[0.029]$} & {$[0.031]$} & {$[0.019]$} & {$[0.024]$} \\
\hline \multirow[t]{2}{*}{ Later year } & $0.268^{* * *}$ & $0.199 * * *$ & $0.394^{* * *}$ & $0.107^{* * *}$ & $0.094^{* * *}$ & $0.237^{* * *}$ \\
\hline & {$[0.016]$} & {$[0.009]$} & {$[0.017]$} & {$[0.010]$} & {$[0.012]$} & {$[0.024]$} \\
\hline \multirow[t]{2}{*}{ Male $\times$ later year } & 0.016 & $-0.044^{* *}$ & 0.034 & $-0.100^{* * *}$ & $-0.080^{* * *}$ & $-0.208^{* * *}$ \\
\hline & {$[0.021]$} & {$[0.021]$} & {$[0.033]$} & {$[0.032]$} & {$[0.026]$} & {$[0.032]$} \\
\hline$N$ & 8266 & 13,005 & 4407 & 12,878 & 6128 & 5496 \\
\hline$r^{2}$ & 0.195 & 0.223 & 0.265 & 0.053 & 0.102 & 0.132 \\
\hline Female baseline value & 0.122 & 0.264 & 0.232 & 0.778 & 0.680 & 0.388 \\
\hline
\end{tabular}

Sample: respondents aged 15-20 years in the DHS survey. The dependent variable takes the value 1 if the respondent at least started secondary education or passes the literacy test and zero if not. Controls include year-specific age dummies, regional dummies interacted with urban/rural, household size and number of household members less than 5 years. *** and ** reflect conventional significance at 1 and $5 \%$ levels

household. The interaction term provides a difference in difference analysis, examining how gender gaps have changed over time.

The results for the key dummy variables in these regressions are reported in Table 6 (for educational outcomes) and Table 7 (for work outcomes), along with the baseline values for females the outcome variables. We have estimated the same regressions without the controls in order to see the raw figures, but the results are very similar to those presented here and so are not shown.

In terms of secondary education, the baseline values are highest in Kenya and Uganda and lowest in Burkina Faso and Tanzania. Over the periods considered, there have been substantial improvements over time in Ghana and quite large improvements in Kenya and Tanzania and smaller though still statistically significant in increases in Uganda and Burkina Faso. In the base years, significantly more young men had some secondary education in all countries except Ghana and Tanzania, but by the later year, the gender gap was eliminated in Kenya and Uganda. These two countries plus Ghana do not have a significant gender gap in this outcome in the latest year, but in the other three countries, the gender gap in this outcome has not fallen and significantly more men than women have some secondary education in the latest year. This is even in the case in Tanzania where there was not a significant differential at baseline.

Some similar patterns apply to literacy. In all countries, rates have increased significantly between the earlier and later year, and the increases have been substantial in terms of Ghana, Burkina Faso and Uganda in particular. In all countries except Ghana, young men 
Table 7 Regressions for job outcomes based on pooled country-level data

\begin{tabular}{|c|c|c|c|c|c|c|}
\hline Coefficient & Burkina Faso & Ethiopia & Ghana & Kenya & Tanzania & Uganda \\
\hline \multicolumn{7}{|c|}{ If individual has a professional, managerial, technical or clerical (white-collar) job } \\
\hline \multirow[t]{2}{*}{ Male } & $0.016^{* *}$ & 0.013 & $0.032^{*}$ & 0.003 & $0.011^{*}$ & -0.002 \\
\hline & {$[0.007]$} & {$[0.009]$} & {$[0.018]$} & {$[0.011]$} & {$[0.006]$} & {$[0.009]$} \\
\hline \multirow[t]{2}{*}{ Later year } & $0.037^{* * *}$ & $0.029^{* * *}$ & $0.062^{* * *}$ & $-0.026^{* * *}$ & $0.027^{* * *}$ & $0.041^{* * *}$ \\
\hline & {$[0.006]$} & {$[0.004]$} & {$[0.010]$} & {$[0.007]$} & {$[0.003]$} & {$[0.009]$} \\
\hline \multirow[t]{2}{*}{ Male $\times$ later year } & $0.014^{*}$ & -0.003 & 0.012 & $0.066^{* * *}$ & 0.002 & -0.020 \\
\hline & {$[0.008]$} & {$[0.010]$} & {$[0.021]$} & {$[0.012]$} & {$[0.008]$} & {$[0.013]$} \\
\hline N & 9710 & 14,520 & 5648 & 16,742 & 6977 & 6692 \\
\hline$r^{2}$ & 0.048 & 0.092 & 0.081 & 0.028 & 0.046 & 0.041 \\
\hline Female baseline value & 0.015 & 0.025 & 0.037 & 0.115 & 0.015 & 0.033 \\
\hline \multicolumn{7}{|c|}{ If individual works in agriculture } \\
\hline \multirow[t]{2}{*}{ Male } & $0.314^{* * *}$ & $0.405^{* * *}$ & $0.237^{* * *}$ & $0.233^{* * *}$ & $0.265^{* * *}$ & $0.220^{* * *}$ \\
\hline & {$[0.019]$} & {$[0.017]$} & {$[0.022]$} & {$[0.013]$} & {$[0.019]$} & {$[0.020]$} \\
\hline \multirow[t]{2}{*}{ Later year } & $-0.120^{* * *}$ & $-0.109^{* * *}$ & $-0.090^{* * *}$ & $-0.126^{* * *}$ & $0.146^{* * *}$ & $0.044^{* *}$ \\
\hline & {$[0.016]$} & {$[0.008]$} & {$[0.012]$} & {$[0.009]$} & {$[0.011]$} & {$[0.020]$} \\
\hline \multirow[t]{2}{*}{ Male $\times$ later year } & $-0.158^{* * *}$ & 0.013 & $-0.107^{* * *}$ & $-0.129^{* * *}$ & $-0.271^{* * *}$ & 0.015 \\
\hline & {$[0.022]$} & {$[0.018]$} & {$[0.025]$} & {$[0.015]$} & {$[0.026]$} & {$[0.028]$} \\
\hline$N$ & 9710 & 14,520 & 5648 & 16,742 & 6977 & 6692 \\
\hline$r^{2}$ & 0.303 & 0.355 & 0.308 & 0.106 & 0.353 & 0.207 \\
\hline Female baseline value & 0.380 & 0.371 & 0.318 & 0.195 & 0.421 & 0.439 \\
\hline
\end{tabular}

Sample: respondents aged 21-29 years in the DHS survey. The dependent variable takes the value 1 if the respondent works in a white-collar job/agriculture and zero if not. Controls include year-specific age dummies, regional dummies interacted with urban/rural, household size and number of household members less than 5 years. ***, ** and *reflect conventional significance at 1,5 and $10 \%$ levels

were significantly more likely to be literate than young women in the earlier year, but again, the gap has been eliminated or more than eliminated in Kenya and Uganda as well as Tanzania. Significant gender gaps remain in Burkina Faso and Ethiopia in the latest years. But the general pattern across these countries is of falling gender differentials in educational outcomes over time; some countries are just progressing more quickly than others and/or were more unequal to start with. Repeating this analysis for more limited (15 to 18) or wider (15 to 22) age ranges shows the same patterns as displayed in Table 6.

Turning to jobs for those in the 21-30 age range, the baseline figures for those having professional, managerial, technical and clerical jobs are very low everywhere, except Kenya where $11.5 \%$ of $21-29$-year-old females have such jobs. The numbers in these jobs have increased significantly over time in all countries except Kenya (where they appear to have fallen significantly). The increases, though small in percentage points, are often large given the low baselines, as for example in Ghana, Uganda and Burkina Faso. There is a weakly significant gender differential in favour of men in the base year in Burkina Faso, Ghana and Tanzania. But there is no evidence of gender gaps falling here, and they appear to have increased significantly in Kenya and to a lesser extent Burkina Faso.

In all countries except Kenya, one third or more of all 21-29-year-old females (including those that did not work) worked in agriculture in the base year and more than $40 \%$ in Tanzania and Uganda. The numbers having agricultural jobs increased over time in Tanzania and Uganda but fell in the other countries. Men were much more likely to do these jobs in the base year everywhere; in Tanzania, women have caught up with men by 
the later year, while in Burkina Faso, Ghana and Kenya, they reduced the gender differential.

Over time, educational outcomes have substantially improved everywhere over the periods considered. The gender gaps have been eliminated, reduced or were never present in four of the countries; only in Burkina Faso and Ethiopia is there a persistent gender gap in educational outcomes. But over the same period, there has been substantially less progress in terms of work outcomes. Only in Ghana has there been significant movement out of agricultural and movement into white-collar type jobs. Burkina Faso and Ethiopia show more limited progress in this area. It is clear that the number able to obtain the white collar jobs is substantially less than those who potentially could have the required levels of education for these positions.

If age ranges of 15 to 24 are considered for the work model, the evidence of the narrowing gender gap in agricultural work in Ghana is no longer significant, while there is evidence of an increasing differential in favour of males in doing agricultural work in Ethiopia and Uganda. Other than that, the results are similar. The models for white-collar work suffer from having a much smaller number of observations (few people clearly obtaining such jobs by age 24), but the messages are still broadly similar.

Overall, some more gender gaps are evident in relation to work than was the case for education. Of course, this may take more time, but fertility is also a very important factor that may limit the opportunities for women to work. There is also evidence of limited growth in opportunities for young educated workers, and in Tanzania and Uganda, there has been movement of workers into agriculture. Opportunities for work outside of agriculture seem to lag far behind the growth of educational completion.

\section{Partial correlations via linear probability models}

In this section, we explore partial or conditional correlations between the same four key outcome variables and a common set of explanatory variables. The samples are, as before, of young people aged 15 to 29 in our 12 DHS datasets from six countries, separating male and female respondents. As before, the two work variables are considered for those aged 21-30 years, while the educational outcomes are analysed for those aged 15-20 years.

The key common correlates considered are as follows: a set of age controls, controls for region interacted with urban/rural location, the gender of the head of household, the number of children aged under 5 years in the household (not necessarily the children of the young woman or man), a household wealth index discussed above and whether the young person is married. Early experiments interacted being married with all the other household variables. The reason for these interaction terms is, as we have shown, young women in particular mostly get married within the age band we have chosen; indeed, many marry in their early 20s. Interaction terms allow young single respondent living at home and a married respondent living in a newly established household to be included in the same regression without the imposition of common parameters. Of course, the estimated parameters, such as the effect of household wealth on occupational choice, may not differ systematically enough for the regressions to pick them up. In the light of that, we allowed ourselves some simplification of the specification, eliminating interactions that were clearly uninformative.

Of course, a number of these explanatory variables, and in particular marriage, will be endogenous; our focus here is only on associations. 
Table 8 Selected LPM regression coefficients: dependent variable: holds a white-collar job

\begin{tabular}{|c|c|c|c|c|c|c|c|c|}
\hline Country & Year & Sex & Married & Wealth & Married $\times$ wealth & HH size & No. aged < 5 & Ns \\
\hline \multirow[t]{4}{*}{ Burkina Faso } & 1998 & W & -0.011 & $0.039^{* * *}$ & 0.000 & -0.000 & -0.002 & 1929 \\
\hline & & M & $-0.077^{* * *}$ & $0.094^{* * *}$ & -0.000 & $-0.009^{* * *}$ & $0.017^{* * *}$ & 678 \\
\hline & 2010 & w & $-0.035^{* * *}$ & $0.026^{* * *}$ & 0.015 & -0.000 & -0.003 & 5335 \\
\hline & & M & $-0.034^{* *}$ & $0.051^{* * *}$ & 0.034 & $-0.005^{* * *}$ & 0.008 & 1596 \\
\hline \multirow[t]{4}{*}{ Ethiopia } & 2000 & W & -0.004 & $0.079^{* * *}$ & 0.002 & 0.000 & $-0.009^{* * *}$ & 4741 \\
\hline & & M & 0.022 & $0.119^{* * *}$ & 0.034 & 0.002 & -0.011 & 688 \\
\hline & 2011 & W & $-0.045^{* * *}$ & $0.167^{* * *}$ & $-0.042^{* * *}$ & $-0.010^{* * *}$ & $-0.017^{* * *}$ & 5158 \\
\hline & & M & -0.013 & $0.149^{* * *}$ & 0.029 & $-0.010^{* * *}$ & $-0.012^{*}$ & 3845 \\
\hline \multirow[t]{4}{*}{ Ghana } & 1993 & W & $-0.022^{*}$ & $0.022^{* *}$ & 0.004 & $-0.003^{*}$ & -0.001 & 1450 \\
\hline & & M & $-0.074^{* *}$ & $0.079^{* *}$ & -0.043 & $-0.019^{* *}$ & 0.025 & 336 \\
\hline & 2014 & W & $-0.053^{* * *}$ & $0.145^{* * *}$ & $-0.052^{* * *}$ & 0.002 & $-0.030^{* * *}$ & 2816 \\
\hline & & M & $-0.106^{* * *}$ & $0.187^{* * *}$ & 0.013 & 0.003 & 0.007 & 1027 \\
\hline \multirow[t]{4}{*}{ Kenya } & 1993 & W & -0.001 & $0.083^{* * *}$ & $0.064^{* * *}$ & -0.004 & 0.008 & 1306 \\
\hline & & M & -0.002 & $0.078^{* * *}$ & 0.027 & -0.007 & -0.006 & 778 \\
\hline & 2014 & W & $-0.056^{* * *}$ & $0.055^{* * *}$ & $0.036^{* *}$ & $-0.007^{* *}$ & $-0.016^{* *}$ & 4812 \\
\hline & & M & -0.027 & $0.081^{* * *}$ & -0.008 & $-0.007^{*}$ & 0.003 & 3423 \\
\hline \multirow[t]{4}{*}{ Tanzania } & 1996 & W & 0.002 & $0.012^{*}$ & 0.008 & 0.000 & 0.001 & 2523 \\
\hline & & M & 0.008 & $0.040^{*}$ & 0.032 & 0.000 & 0.001 & 561 \\
\hline & 2010 & W & $-0.021^{* *}$ & $0.060^{* * *}$ & -0.011 & $-0.002^{*}$ & 0.001 & 3035 \\
\hline & & M & -0.037 & 0.034 & 0.022 & -0.005 & 0.009 & 650 \\
\hline \multirow[t]{4}{*}{ Uganda } & 1995 & W & $-0.037^{* * *}$ & $0.037^{* * *}$ & 0.006 & $-0.003^{*}$ & -0.004 & 2468 \\
\hline & & M & -0.011 & $0.051^{* *}$ & -0.024 & 0.000 & -0.007 & 642 \\
\hline & 2011 & W & -0.012 & $0.092^{* * *}$ & -0.004 & $-0.005^{* *}$ & $-0.010^{*}$ & 2891 \\
\hline & & M & -0.037 & $0.093^{* * *}$ & 0.002 & -0.002 & 0.002 & 624 \\
\hline
\end{tabular}

LPM denotes linear probability model. Sample: respondents aged 20-29 years in the DHS survey. The dependent variable takes the value 1 if the respondent is working in a professional, managerial, technical or clerical job and zero otherwise. Estimation via the linear probability model. Controls include age and regional, urban and rural dummies. Married is an indicator for the marital status of the respondent. Wealth is a normalised index of household wealth (see text). Married $x$ wealth is the interaction of the two variables. $\mathrm{HH}$ size is the number of people in the household. No. aged $<5$ is the number of children aged under 5 years. ${ }^{* *}, *^{*}$ and * reflect conventional significance at 1,5 and $10 \%$ levels

Results are given in Tables 8, 9, 10, and 11. The initial discussion focusses on the results with respect to six explanatory variables: household size, the number of children aged under 5 years old present in the household, the gender of the head of the household, being married, a household wealth index and an interaction term between wealth and marriage. It is not straightforward to make generalisation which applies to all cases from such a set of results. We take an ad hoc approach, noting results if there is a clear majority of the same sign, irrespective of statistical significance. There are many more sophisticated approaches, but with the relatively small number of countries involved, we think a formal rule on what to note is unnecessary and cumbersome.

First, household size has no general relationship with working in agriculture, but household size is negatively associated with having a white-collar job in many cases. Household size is if anything perhaps mildly positively associated with staying on at school or doing better in a literacy test, but it may be that those in larger households are more likely on average to still be living in their parental home. In several countries, having young children in the house is mildly negatively related to having a white-collar 
Table 9 Selected LPM regression coefficients: dependent variable: works in agriculture

\begin{tabular}{|c|c|c|c|c|c|c|c|c|}
\hline Country & Year & Sex & Married & Wealth & Married $\times$ wealth & HH size & No aged $<5$ & $N$ \\
\hline \multirow[t]{4}{*}{ Burkina Faso } & 1998 & W & $0.129^{* *}$ & -0.028 & $-0.099^{* * *}$ & 0.004 & 0.009 & 1929 \\
\hline & & M & 0.043 & $-0.118^{* * *}$ & -0.033 & -0.006 & $0.033^{* *}$ & 678 \\
\hline & 2010 & W & $0.068^{* * *}$ & $-0.024^{* * *}$ & $-0.063^{* * *}$ & 0.001 & $0.022^{* * *}$ & 5335 \\
\hline & & M & $0.052^{* *}$ & $-0.083^{* * *}$ & $-0.064^{* * *}$ & $0.004^{* * *}$ & $0.020^{*}$ & 1596 \\
\hline \multirow[t]{4}{*}{ Ethiopia } & 2000 & w & $0.065^{* * *}$ & $-0.096^{* * *}$ & $-0.091^{* * *}$ & $0.009^{* *}$ & -0.002 & 4741 \\
\hline & & M & 0.004 & $-0.171^{* * *}$ & $-0.096^{* * *}$ & 0.009 & 0.008 & 688 \\
\hline & 2011 & w & $0.065^{* * *}$ & $-0.065^{* * *}$ & $-0.061^{* * *}$ & 0.004 & $-0.022^{*}$ & 5158 \\
\hline & & M & 0.016 & $-0.212^{* * *}$ & $-0.077^{* * *}$ & 0.000 & 0.009 & 3845 \\
\hline \multirow[t]{4}{*}{ Ghana } & 1993 & W & $0.075^{* * *}$ & $-0.020^{*}$ & $-0.084^{* * *}$ & 0.005 & $0.033^{* *}$ & 1450 \\
\hline & & M & $0.104^{* *}$ & $-0.102^{* * *}$ & $-0.069^{* *}$ & -0.004 & $0.059^{*}$ & 336 \\
\hline & 2014 & W & $0.120^{* * *}$ & $-0.053^{* * *}$ & $-0.127^{* * *}$ & 0.005 & $0.026^{* * *}$ & 2816 \\
\hline & & M & $0.111^{* * *}$ & $-0.181^{* * *}$ & $-0.122^{* * *}$ & 0.009 & -0.001 & 1027 \\
\hline \multirow[t]{4}{*}{ Kenya } & 1993 & W & $0.143^{* * *}$ & $-0.068^{* * *}$ & $-0.050^{* *}$ & -0.008 & 0.007 & 1306 \\
\hline & & M & 0.012 & $-0.101^{* * *}$ & -0.002 & 0.004 & -0.034 & 778 \\
\hline & 2014 & W & $0.107^{* * *}$ & $-0.017^{* *}$ & $-0.047^{* * *}$ & 0.002 & $0.021^{* * *}$ & 4812 \\
\hline & & M & 0.012 & $-0.036^{* * *}$ & $-0.040^{* * *}$ & $0.010^{* * *}$ & -0.003 & 3423 \\
\hline \multirow[t]{4}{*}{ Tanzania } & 1996 & W & -0.022 & $-0.071^{* * *}$ & $0.034^{*}$ & -0.003 & 0.011 & 2523 \\
\hline & & M & 0.016 & $-0.140^{* * *}$ & $-0.068^{* *}$ & -0.001 & 0.016 & 561 \\
\hline & 2010 & W & $0.102^{* * *}$ & $-0.117^{* * *}$ & $-0.079^{* * *}$ & $0.006^{* *}$ & $0.016^{* *}$ & 3035 \\
\hline & & M & 0.067 & $-0.084^{* * *}$ & $-0.094^{* * *}$ & $0.013^{*}$ & -0.007 & 650 \\
\hline \multirow[t]{4}{*}{ Uganda } & 1995 & w & $0.108^{* * *}$ & $-0.027^{*}$ & $-0.076^{* * *}$ & -0.002 & $0.020^{* *}$ & 2468 \\
\hline & & M & 0.054 & $-0.060^{* *}$ & $-0.204^{* * *}$ & $-0.017^{* *}$ & 0.001 & 642 \\
\hline & 2011 & W & 0.026 & $-0.089^{* * *}$ & $-0.100^{* * *}$ & 0.001 & $0.033^{* * *}$ & 2891 \\
\hline & & M & -0.018 & $-0.130^{* * *}$ & -0.065 & 0.006 & 0.023 & 624 \\
\hline
\end{tabular}

LPM denotes linear probability model. Sample: respondents aged 21-29 years in the DHS survey. The dependent variable takes the value 1 if the respondent works in agriculture and zero if not. Estimation via the linear probability model. Controls include age and regional, urban and rural dummies. Married is an indicator for the marital status of the respondent. Wealth is a normalised index of household wealth (see text). Married $\times$ wealth is the interaction of the two variables. $\mathrm{HH}$ size is the number of people in the household. No. aged $<5$ is the number of children aged under 5 years. ${ }^{* *},{ }^{* *}$ and ${ }^{*}$ reflect conventional significance at 1,5 and $10 \%$ levels

job, this effect being much more evident for women, and is positively associated with working in agriculture, again especially for women. But having young children in the household strongly negatively related to passing a literacy test and to staying on at school to the secondary level, again especially for women. Note that we do not report an interaction term between marriage and the presence of children, because the results for this variable were largely insignificant and of variable sign. Thus, having children around reduces the chances of a young woman having received a good education and thus a high-quality job, irrespective of whether the children are likely to be the respondent's own offspring or those of another female house member.

Living in a male-headed household is mildly negatively associated with entering secondary education for women in Burkina Faso, Tanzania and Uganda in the later years, but not for men.

Now, we turn to marital status, household wealth and their interaction. Household wealth is strongly positively related, in almost all country-year combinations, for both females and males, to having entered secondary education and to performing well in 
Table 10 Selected LPM regression coefficients: dependent variable: passes a literacy test

\begin{tabular}{|c|c|c|c|c|c|c|c|c|c|}
\hline Country & Year & Sex & Married & Wealth & Married $\times$ wealth & HH size & No. aged $<5$ & Male head & $N$ \\
\hline \multirow[t]{4}{*}{ Burkina Faso } & 1998 & W & $-0.121^{* * *}$ & $0.079^{* * *}$ & $-0.100^{* * *}$ & 0.000 & -0.006 & -0.050 & 1769 \\
\hline & & M & $-0.219^{* * *}$ & $0.125^{* * *}$ & $-0.189^{* * *}$ & -0.004 & -0.010 & -0.056 & 709 \\
\hline & 2010 & W & $-0.199 * * *$ & 0.016 & 0.029 & $0.008^{* * *}$ & $-0.036^{* * *}$ & $-0.061^{* *}$ & 4081 \\
\hline & & M & $-0.145^{* * *}$ & $0.121^{* * *}$ & 0.060 & -0.000 & -0.011 & -0.036 & 1707 \\
\hline \multirow[t]{4}{*}{ Ethiopia } & 2000 & W & -0.038 & $0.182^{* * *}$ & 0.046 & $0.010^{* * *}$ & $-0.032^{* * *}$ & $-0.053^{* *}$ & 4346 \\
\hline & & M & 0.471 & $0.188^{* * *}$ & 0.787 & -0.002 & -0.041 & 0.066 & 665 \\
\hline & 2011 & W & $-0.195^{* * *}$ & $0.105^{* * *}$ & $0.152^{* * *}$ & 0.004 & $-0.050^{* * *}$ & 0.012 & 4579 \\
\hline & & M & -0.112 & $0.138^{* * *}$ & 0.083 & -0.002 & $-0.027^{*}$ & 0.019 & 3415 \\
\hline \multirow[t]{4}{*}{ Ghana } & 1993 & W & $-0.178^{* * *}$ & $0.058^{* * *}$ & $-0.078^{* *}$ & 0.005 & $-0.053^{* * *}$ & -0.000 & 1017 \\
\hline & & M & -0.152 & $0.137^{* * *}$ & 0.004 & 0.014 & $-0.056^{*}$ & 0.031 & 270 \\
\hline & 2014 & W & $-0.345^{* * *}$ & $0.102^{* * *}$ & -0.003 & -0.004 & $-0.061^{* * *}$ & 0.010 & 2067 \\
\hline & & M & 0.128 & $0.149 * * *$ & $0.308^{* * *}$ & -0.007 & 0.001 & 0.012 & 1053 \\
\hline \multirow[t]{4}{*}{ Kenya } & 1993 & W & $-0.175^{* * *}$ & $0.041^{* * *}$ & $0.128^{* * *}$ & $0.008^{* *}$ & $-0.026^{* *}$ & -0.017 & 2201 \\
\hline & & M & -0.217 & -0.004 & -0.052 & 0.016 & -0.030 & -0.007 & 126 \\
\hline & 2014 & W & $-0.113^{* * *}$ & $0.031 * * *$ & $0.144^{* * *}$ & $0.008^{* * *}$ & $-0.030^{* * *}$ & -0.005 & 7268 \\
\hline & & M & -0.011 & $0.085^{* * *}$ & 0.146 & -0.005 & -0.006 & $0.027^{*}$ & 3283 \\
\hline \multirow[t]{4}{*}{ Tanzania } & 1996 & W & $-0.127^{* * *}$ & $0.052^{* * *}$ & $0.074^{* *}$ & $0.010^{* * *}$ & $-0.047^{* * *}$ & -0.006 & 2115 \\
\hline & & M & 0.023 & $0.067^{* * *}$ & 0.125 & 0.010 & -0.023 & $0.091^{* *}$ & 590 \\
\hline & 2010 & W & $-0.152^{* * *}$ & $0.059 * * *$ & $0.082^{* * *}$ & 0.005 & $-0.024^{* *}$ & -0.003 & 2642 \\
\hline & & M & -0.064 & $0.115^{* * *}$ & 0.044 & 0.005 & -0.032 & 0.017 & 779 \\
\hline \multirow[t]{4}{*}{ Uganda } & 1995 & W & $-0.155^{* * *}$ & $0.065^{* * *}$ & $0.097^{* * *}$ & 0.005 & -0.018 & -0.026 & 2014 \\
\hline & & M & -0.153 & $0.079^{* *}$ & -0.055 & 0.010 & 0.006 & -0.044 & 457 \\
\hline & 2011 & W & $-0.140^{* * *}$ & $0.039^{*}$ & $0.125^{* * *}$ & 0.007 & $-0.038^{* * *}$ & $-0.059^{* *}$ & 2390 \\
\hline & & M & -0.043 & $0.148^{* * *}$ & 0.067 & $0.015^{*}$ & $-0.047^{*}$ & 0.048 & 634 \\
\hline
\end{tabular}

LPM denotes linear probability model. Sample: respondents aged 15-20 years in the DHS survey. The dependent variable takes the value 1 if the respondent passes the functional literacy test, zero otherwise. Estimation via the linear probability model. Controls include age and regional, urban and rural dummies. Married is an indicator for the marital status of the respondent. Wealth is a normalised index of household wealth (see text). Married $\times$ wealth is the interaction of the two variables. $\mathrm{HH}$ size is the number of people in the household. No. aged $<5$ is the number of children aged under 5 years. $* * *, * *$ and ${ }^{*}$ reflect conventional significance at 1,5 and $10 \%$ levels

the literacy test. It is also clear this wealth effect is usually larger for men than women; indeed, this is true in the vast majority of cases. There are predictable strongly significant partial correlations between occupations and wealth: positive and strong for white-collar work and negative and strong for agricultural work, both in almost all cases. It is also notable that a gender gap emerges here too, though not as strongly as for education, but, in most of the six countries, the wealth effects, positive for whitecollar and negative for agriculture work, are stronger for men than for women. Perhaps, this result most clearly illustrated the causality issue that should make us cautious about drawing inference. To illustrate, is it that a poor household is more likely to send a young man than a young woman into the fields or that a household is more likely to be poorer if it contains male rather than female agricultural workers? Both ways around seem plausible.

It is particularly a weaker effect for unmarried women, as married women seem to experience less of a reduction in the wealth effect compared to men. In contrast, we find no systematic difference in wealth effects between single and married men. 
Table 11 Selected LPM regression coefficients: dependent variable: has some secondary education

\begin{tabular}{|c|c|c|c|c|c|c|c|c|c|}
\hline Country & Year & Sex & Married & Wealth & Married $\times$ wealth & HH size & No aged $<5$ & Male head & $N$ \\
\hline \multirow[t]{4}{*}{ Burkina Faso } & 1998 & W & $-0.103^{* * *}$ & $0.082^{* * *}$ & $-0.086^{* * *}$ & 0.001 & $-0.009^{*}$ & -0.035 & 1770 \\
\hline & & M & $-0.182^{* * *}$ & $0.139 * * *$ & $-0.195^{* * *}$ & -0.004 & -0.007 & -0.085 & 710 \\
\hline & 2010 & W & $-0.156^{* * *}$ & $0.038^{* * *}$ & 0.002 & $0.008^{* * *}$ & $-0.036^{* * *}$ & $-0.058^{* *}$ & 4127 \\
\hline & & M & $-0.107^{* *}$ & $0.131^{* * *}$ & $0.069^{*}$ & -0.003 & -0.009 & -0.031 & 1741 \\
\hline \multirow[t]{4}{*}{ Ethiopia } & 2000 & W & -0.015 & $0.154^{* * *}$ & 0.008 & $0.005^{*}$ & $-0.028^{* * *}$ & -0.028 & 4394 \\
\hline & & M & $-0.223^{* * *}$ & $0.170^{* * *}$ & $-0.220^{* *}$ & $0.009^{*}$ & -0.017 & 0.001 & 667 \\
\hline & 2011 & W & $-0.077^{* * *}$ & $0.088^{* * *}$ & -0.005 & 0.002 & $-0.039^{* * *}$ & -0.020 & 4841 \\
\hline & & M & $-0.139^{*}$ & $0.170^{* * *}$ & -0.115 & -0.004 & $-0.015^{*}$ & 0.010 & 3557 \\
\hline \multirow[t]{4}{*}{ Ghana } & 1993 & W & $-0.142^{* * *}$ & $0.069^{* * *}$ & $-0.058^{* *}$ & -0.006 & -0.014 & 0.026 & 1017 \\
\hline & & M & $-0.205^{* * *}$ & $0.119^{* * *}$ & $-0.188^{*}$ & $0.020^{* *}$ & -0.018 & -0.036 & 270 \\
\hline & 2014 & W & $-0.204^{* * *}$ & $0.063^{* * *}$ & $0.135^{* * *}$ & -0.002 & $-0.057^{* * *}$ & 0.023 & 2071 \\
\hline & & M & 0.053 & $0.164^{* * *}$ & $0.273^{* * *}$ & -0.002 & -0.009 & 0.034 & 1054 \\
\hline \multirow[t]{4}{*}{ Kenya } & 1993 & W & $-0.189^{* * *}$ & $0.082^{* * *}$ & -0.006 & 0.006 & $-0.037^{* * *}$ & -0.027 & 2208 \\
\hline & & M & -0.106 & 0.050 & 0.198 & $0.033^{* *}$ & -0.025 & -0.041 & 126 \\
\hline & 2014 & W & $-0.265^{* * *}$ & $0.098^{* * *}$ & $0.060^{* *}$ & $0.010^{* * *}$ & $-0.091^{* * *}$ & 0.008 & 7303 \\
\hline & & M & $-0.399^{* * *}$ & $0.192^{* * *}$ & $-0.441^{* *}$ & $-0.009^{*}$ & -0.016 & -0.002 & 3291 \\
\hline \multirow[t]{4}{*}{ Tanzania } & 1996 & W & $-0.035^{* * *}$ & $0.061^{* * *}$ & 0.020 & 0.003 & $-0.019^{* * *}$ & $-0.034^{* *}$ & 2120 \\
\hline & & M & $-0.133^{* * *}$ & $0.092^{* * *}$ & $-0.128^{* * *}$ & 0.002 & -0.013 & -0.020 & 590 \\
\hline & 2010 & W & $-0.299^{* * *}$ & $0.099^{* * *}$ & $-0.084^{* * *}$ & $0.010^{* * *}$ & $-0.048^{* * *}$ & $-0.057^{* *}$ & 2657 \\
\hline & & M & $-0.356^{* * *}$ & $0.191^{* * *}$ & $-0.192^{* * *}$ & 0.006 & $-0.064^{* * *}$ & -0.054 & 781 \\
\hline \multirow[t]{4}{*}{ Uganda } & 1995 & W & $-0.138^{* * *}$ & $0.080^{* * *}$ & 0.014 & $0.010^{* * *}$ & $-0.029^{* * *}$ & -0.019 & 2015 \\
\hline & & M & $-0.141^{*}$ & $0.129^{* * *}$ & 0.060 & $0.011^{*}$ & -0.013 & -0.074 & 459 \\
\hline & 2011 & W & $-0.186^{* * *}$ & $0.097^{* * *}$ & 0.049 & $0.009^{*}$ & $-0.050^{* * *}$ & $-0.071^{* * *}$ & 2416 \\
\hline & & $M$ & -0.085 & $0.130^{* * *}$ & 0.080 & 0.013 & $-0.046^{*}$ & -0.012 & 643 \\
\hline
\end{tabular}

LPM denotes linear probability model. Sample: respondents aged 15-20 years in the DHS survey. The dependent variable takes the value 1 if the respondent at least started secondary education and zero if not. Estimation via the linear probability model. Controls include age and regional, urban and rural dummies. Married is an indicator for the marital status of the respondent. Wealth is a normalised index of household wealth (see text). Married $\times$ wealth is the interaction of the two variables. HH size is the number of people in the household. No. aged $<5$ is the number of children aged under 5 years. $*^{* *}, * *$ and $*$ reflect conventional significance at 1,5 and $10 \%$ levels

Holding wealth constant, marriage is associated with lower education and literacy, for both men and women, with the reduced literacy scores being particularly striking for women. Married women in particular are significantly more likely to work in agriculture and less likely to have a white-collar job. The interaction terms show that a household having wealth above the average offsets or reverses the positive association between being married and working on agriculture, for both females and males, but this interaction is less significant in other cases.

\section{Conclusions}

Across all the six countries considered here, there has been impressive progress in the last 10-20 years in improving educational attendance and attainment, and the gender gaps considered here have been reduced or are no longer present in four of the six countries. This has been an impressive achievement, and even if there are legitimate concerns about educational quality, literacy rates have improved significantly. The progress in terms of access to better quality jobs though has been slower, with only 
really evidence of significant levels of these jobs for young people in Ghana and Kenya. Gender gaps also persist in relation to work in many countries and also in higher levels of education. In short, there has been impressive progress in education but much more limited progress in relation to jobs-though not none. But the youth employment challenge remains a very serious one.

The presence of young children is associated with lower levels of education, literacy and lower rates of taking white-collar jobs for women across these six countries. As far as we can tell, this happens irrespective of whether the respondent is married and thus more likely to be the mother. This result suggests that the traditional caring role of women may lead to decisions that worsen a young woman's employment consequences. Of course, reverse causality is possible here, with less academically able people choosing to start families earlier or, at least, those living in places where the benefits of staying on at school are less obvious choosing to start families earlier. But it seems very likely that domestic responsibilities weigh heavily on young women's choices.

There is a strong positive relationship between household wealth and (1) entering secondary education, (2) literacy score and (3) obtaining a white-collar job. Of course, we must be conscious of the possibility of reverse causality here too, with bright people getting good jobs and building up more assets and so on, but, again, it seems likely that the lower pressure to start work, or get married earlier that comes with family wealth, reaps benefits in terms of longer time spent in education, great literacy and more good jobs. The size of this effect is much larger for men, so young men's life chances seem to improve faster with household wealth.

If we can take household wealth as a family background variable, then the strong relationships from wealth to literacy and education and onto "white-collar work" suggest a channel whereby inequality may develop further, particularly if, as seems to be the case, demand for "skilled" workers does not keep up with supply. This is particularly important for women, as almost certainly, the route to closing gender gaps in work, education and pay is through the development of sectors like health, education, financial and business services, for instance. These are the sectors around the world that tend to employ and attract skilled women.

\section{Endnotes}

${ }^{1}$ According to many indicators, Ghana and Kenya would be the most developed of the countries considered here, with Burkina Faso and Ethiopia the least developed (though both have known significant growth in recent years). Tanzania and Uganda are in several respects intermediate between these four. These rankings though do depend to some extent on the criteria considered. Most of these countries have experienced significant periods of economic growth over the past 20 years, though in the case of Kenya, this has been uneven over time.

${ }^{2}$ While the ILO's School to Work Transition Survey (Elder 2009), which has sought to collect information on the key variables of relevance to this transition, might have been a suitable source for such an analysis, this was only conducted in one of our focus countries (Uganda). 
del Pozo Seguro for the excellent research assistance support in relation to this work. We would also like to thank the anonymous referee and the editor for the useful remarks.

Responsible editor: David Lam

\section{Competing interests}

The IZA Journal of Development and Migration is committed to the IZA Guiding Principles of Research Integrity. The authors declare that they have observed these principles.

\section{Publisher's Note}

Springer Nature remains neutral with regard to jurisdictional claims in published maps and institutional affiliations.

\section{Author details}

${ }^{1}$ Partnership for Economics Policy (PEP) and University of Nairobi, University Way, Nairobi, Kenya. ${ }^{2}$ Department of Economics, University of Sussex, Brighton BN1 9SL, UK. ${ }^{3}$ IZA, Bonn, Germany. ${ }^{4}$ King's College, Strand, London WC2R 2LS, UK.

Received: 19 May 2017 Accepted: 20 February 2018

Published online: 28 August 2018

\section{References}

African Development Bank, OECD Development Centre, United Nations Development Programme and United Nations Economic Commission for Africa (2012), African Economic Outlook, 2012.

Agüero JM, Marks MS. Motherhood and female labor supply in the developing world evidence from infertility shocks. J Hum Resour. 2011;46(4):800-26.

Ardington C, Menendez A, Mutevedzi T. Early childbearing, human capita attainment and mortality risk: evidence from a longitudinal demographic surveillance area in KwaZulu-Natal, South Africa. Econ Dev Cult Chang. 2015;63(2):281-317.

Elder S. ILO school-to-work transition survey: a methodological guide. International Labour Office, Geneve: ILO; 2009.

Elder, S. and S. Kring (2016), Young and female-a double strike? Gender analysis of school-to-work transition surveys in 32 developing economies, Work4Youth Publication Series No. 32, International Labour Organisation.

Filmer D, Fox L. Youth employment in sub-Saharan Africa. Washington, DC: World Bank and Agence Française de Développement; 2014. Available at: http://documents.worldbank.org/curated/en/301371468003940792/pdf/ ACS81330WPOP12977300Box385165B00PUBLIC0.pdf.

Heath and Mobarek. Manufacturing growth and the lives of Bangladeshi women. J Dev Econ. 2015;115:1-15.

Kabeer N. Women's economic empowerment and inclusive growth: labour markets and enterprise development. Canada: SIG Working Paper 2012/1, IDRC; 2012.

Macro International (2006), Guide to DHS statistics.

Marchetta F, Sahn D. The role of education and family background in marriage, childbearing and labor market participation in Senegal, Economic Development and Cultural Change. 2016;64(2):369-403.

O'Higgins N. (2017). Rising to the youth employment challenge: New evidence on key policy issues, International Labour Organisation.

Ozier, O. W. (2015). The impact of secondary schooling in Kenya: a regression discontinuity analysis. World Bank Policy Research Working Paper, (7384).

Parent, D. (2006), Youth labor market in Burkina Faso: recent trends, World Bank Social Protection Discussion Paper No 0607.

Ranchhod, V., Lam, D., Leibbrandt, M., \& Marteleto, L. (2011). Estimating the effect of adolescent fertility on educational attainment in Cape Town using a propensity score weighted regression. Available at: http://www.opensaldru.uct.ac za/handle/11090/58.

Shamchiyeva, L., T. Kizu and G. Kahyarara (2014), Labour market transitions of young women and men in the United Republic of Tanzania, International Labour Office, Work4Youth Publication Series No. 26, December 2014.

Wekwete N. Gender and economic empowerment in Africa: evidence and policy issues. J Afr Econ. 2014;23(suppl 1):i87-i127.

\section{Submit your manuscript to a SpringerOpen ${ }^{\circ}$ journal and benefit from:}

- Convenient online submission

- Rigorous peer review

- Open access: articles freely available online

- High visibility within the field

- Retaining the copyright to your article 